\title{
Conservation biological control and the management of biological control services: are they the same?
}

\author{
Moshe Coll
}

Received: 6 November 2008 / Accepted: 22 February 2009/Published online: 27 March 2009

(C) Springer Science + Business Media B.V. 2009

\section{Biography}

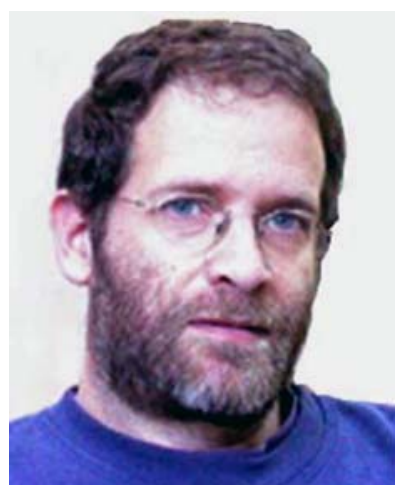

Moshe Coll, born in Israel in 1957, is an Associate Professor of Insect Ecology, Department of Entomology, The Hebrew University of Jerusalem (HUJI), Rehovot. He received his B.Sc. in Biology (1982) and

M. Coll $(\bowtie)$

Department of Entomology,

The Hebrew University of Jerusalem,

P.O. Box 12, Rehovot 76100, Israel

e-mail: coll@agri.huji.ac.il
M.Sc. in Zoology (1985) from Tel-Aviv University, and his PhD. (1991) in Entomology from the University of Maryland, College Park, MD, USA (UMD). He was a Research Entomologist (19921994, US Department of Agriculture); Adjunct Assistant Professor (1993-1994, UMD); Senior Lecturer (1997-2007, HUJ); and Visiting Scientist (20012002, Macquarie University, Australia). His research interests involve the ecology and behavior of insects, and biological and integrated control of agricultural pests. He studies, in particular, interaction between herbivores and their natural enemies, ecological consequences of omnivory and antagonistic interactions between natural enemies. He co-edited a book and has authored or co-authored approximately 60 book chapters and peer-reviewed papers. He teaches four courses, has mentored some 40 graduate students and post-docs, is the academic head of the International M.Sc. Program in Plant Sciences (HUJ), and has served as a subject editor for Biological Control.

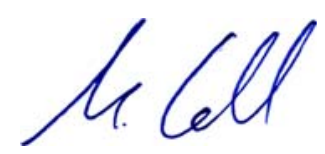


Conservation biological control (CBC) is among the earliest documented pest control measures, dating to third century BC China, where bamboo poles were placed between trees in orchards to facilitate dispersal of predatory ants, thus enhancing predation of citrus pests (Coulson et al. 1982). Recently, conservation biologists have recognized the importance of biological control services (BCS) as one of the many ecosystem services (ES) that natural habitats provide for humans (Costanza et al. 1997; Daily 1997; Pimentel et al. 1997), and estimated the annual value of BCS in the United States alone at $\$ 4.5$ billion to $\$ 17$ billion (Losey and Vaughan 2006; Pimentel et al. 1997). Do conservation biologists and biocontrol practitioners act similarly to promote biocontrol by naturally occurring enemies? I think not. There are some fundamental differences in perspective, goals, approaches and scales, warranting separate terminology, research and application. Yet both fields would benefit from constructive interdisciplinary discussion, and pest management would be improved by the development of unifying predictions and a combined approach to landscape management. These are the issues I explore in this essay.

$\mathrm{CBC}$ is a pest management approach based on manipulation of agroecosystems to promote pest suppression by naturally occurring predators, parasitoids and pathogens (Barbosa 1998). This approach has received much interest in recent years because: (1) it does not involve introducing exotic organisms into the environment, thus avoiding some major environmental concerns associated with classical biocontrol; and (2) when successful, it provides a sustainable pest control solution free of the continuous input of mass-reared natural enemies required by augmentative biocontrol.

While curbing insecticide use is a fundamental goal of any biological control approach, manipulation of properties of crop and non-crop vegetation lies at the heart of $\mathrm{CBC}$. Plant traits mediate many of the interactions between herbivorous pests and their natural enemies: plants often provide predators and parasitoids with water and nourishment in the form of alternative prey and hosts, nectar, pollen and sap. Plants may provide natural enemies with shelter and overwintering sites, and greatly influence the ability of natural enemies to forage effectively (Coll 1998a, b). Much effort has thus been devoted to tailoring the genetics, aboveground structure, phenology, density, and spatio-temporal composition of the vegetation to the needs of naturally occurring enemies. Indeed, considering plant-enemy interactions has been advocated for crop-breeding programs (Bottrell et al. 1998).

Over the last decade or so, more attention has been devoted to BCS and other ES as their importance for promoting biodiversity conservation has been recognized. It is proposed that biodiversity conservation is imperative if we are to benefit from free BCS and other ES. ES are threatened, however, by biodiversity loss which is attributed primarily to agricultural practices such as soil cultivation and pesticide use, and to the rapid anthropogenic disappearance of natural ecosystems. To enhance ES such as biological control and pollination services, the vegetation is often manipulated in landscapes that include crop fields. Although $\mathrm{CBC}$ programs also manipulate vegetation properties to favor biological control, the two approaches differ in several important ways.

The first difference between $\mathrm{CBC}$ and the management of BCS involves the scale at which ecological processes are considered. $\mathrm{CBC}$ tends to focus on a specific crop field, and vegetation is manipulated within that field, along its borders, and within a few adjacent fields within a farming unit. On this scale, activity of natural enemies may be enhanced by increasing taxonomic diversity of plants within the field through mixed cropping, intercropping, and strip cropping. Alternatively, some weeds may be allowed as undergrowth, particularly in perennial crops, and a staggered planting schedule may be adopted. These manipulations of plants within the field can provide natural enemies with food, shelter and a favorable microclimate. Wild and cultivated vegetation may also be manipulated near field margins to provide natural enemies with similar resources by, for example, planting flowering plants along field borders, or creating hedges suitable for the overwintering of predators near annual crops.

Discussion of BCS, in contrast, usually takes a broader perspective of agroecosystems and seeks to promote the conservation of enemy diversity at the landscape level. Agricultural landscapes range from structurally simple areas dominated by a single cropping system, to complex areas with diverse cropping systems embedded in a natural habitat matrix. In complex landscapes, natural enemies provide effective pest control while moving among habitats that provide them with spatio-temporal refugia and resources when these are scarce in crop fields. At this 
scale, a matrix of natural and semi-natural land is managed to enhance biological suppression of pests in agricultural fields situated in a mosaic of habitat types. It is often assumed that greater natural enemy diversity is correlated with more effective biological pest suppression. This assumption, however, has been closely scrutinized and much discussed in recent years (e.g. Müller and Brodeur 2002; Straub et al. 2008).

A second difference between $\mathrm{CBC}$ and the management of BCS is found in their respective practical approaches. CBC often attempts to enhance the activity of one or a few key natural enemies, whereas BCS usually deals with the community as a whole. In fact, Losey and Vaughan (2008) argue that ecosystem “...services are almost always provided by a complex of species." In addition, CBC encompasses practices that reduce mortality, provide supplementary resources, or facilitate effective foraging by natural enemies. To that end, a mechanistic understanding of enemypest interactions is needed. Studies of BCS are usually not directed at unraveling the particular components of the natural habitat responsible for higher enemy impact on pest populations (but see Thies and Tscharntke 1999). These studies focus instead on species diversity of enemy communities, and their contribution to pest control. The relationship between enemy species diversity and the BCS they provide has lately been much debated (Straub et al. 2008). A positive relationship may be the result of facilitation (i.e. the action of one enemy facilitates the function of another) or complementarity (various natural enemies attack pests at different times and places). The absence of a relationship between enemy diversity and BCS may suggest redundancy, where different enemy species act in a similar way to suppress the pest. Finally, a negative connection may result from intraguild predation, in which natural enemies feed on each other in addition to feeding on the pest (Straub et al. 2008). The direct positive effects of vegetation on pest populations, which often counteract any enhancement of enemy activity, also constitute an obstacle to drawing inferences on BCS from community level responses to landscape characteristics.

From an agricultural perspective, the most obvious conflict between $\mathrm{CBC}$ and conservation biology is that the latter may require that some land be taken out of production and allowed to revert to a natural state in order for the system to provide sustainable BCS. This conflict is particularly important in areas where high-value crops are cultivated. In addition, enhanced diversity and abundance of natural enemies may not necessarily result in pest suppression and a decrease in crop damage, because pests and crops also respond to landscape complexity, and they may do so in a way that counteracts the beneficial action of natural enemies. Tscharntke et al. (2005) in fact suggested that $\mathrm{CBC}$ may be most effective in relatively simple landscapes where natural enemies are forced to feed on pests. On the other hand, the management of agricultural areas is vital for maintaining biodiversity because crops often occupy large areas of the landscape.

Finally, both conservation biologists and biological control practitioners must make their work more relevant to stakeholders if it is to be applied. Yet many landscape ecologists working on BCS lack pest management experience, and they do not generally work with farmers or even communicate with them. Likewise, most biological control practitioners do not have the time or expertise to investigate the mechanisms underlying insect community dynamics at the landscape level.

Despite these apparent differences, much could be gained by cross-discipline discussion and collaboration between proponents of $\mathrm{CBC}$ and the management of BCS. The encouragement of diverse enemy communities through increased habitat diversity and connectivity between crop and non-crop habitats may be best for both long-term biological pest suppression and sustainable crop production. According to the insurance hypothesis, species richness can buffer against spatio-temporal disturbances, thereby ensuring stable levels of pest suppression in changing environments (Tscharntke et al. 2007). Additionally, most pests and natural enemies exploit their habitats at spatial scales much larger than a crop field and its immediate surroundings. For the most part, however, current $\mathrm{CBC}$ practices ignore the effect of large-scale dispersal on pest and enemy species (Landis et al. 2000).

Only when we gain a thorough understanding of system function over spatial scales much larger than the single field or farm, will we be able to make specific recommendations about crop combination, spatial arrangement, and association with unmanaged habitats that would provide sustainable and agriculturally viable natural biological control. However, idiosyncratic behavior of multitrophic interactions in time and space impede our ability to generate broad 
generalizations regarding the role of habitat composition and spatial arrangement in agricultural landscapes. To take full advantage of naturally occurring pest enemies, we must therefore identify principal BCS providers, the key environmental factors that influence their activity, and the spatio-temporal scale over which they operate (Kremen 2005).

Habitat management has traditionally been viewed as a single practice, usually aimed at enhancing CBC. Ecosystems, however, also provide a range of additional services to humans, such as restoration of rare ecosystems, protection of endangered species, preservation of undeveloped areas for ecotourism and recreation, and protection of human heritage sites (Fiedler et al. 2008). Moreover, decisions regarding landscape planning and management reflect the contrasting interests of stake-holders within the BCS-providing landscape (Zhang et al. 2007). Not only ecological but also socioeconomical considerations must therefore influence any management recommendation (Letourneau 1998). A broader view of ES may thus facilitate large-scale management of landscapes to promote $\mathrm{CBC}$.

In conclusion, this editorial highlights the need for scientists and practitioners involved in $\mathrm{CBC}$ and BCS to communicate with each other, collaborate, and take full advantage of their complementary perspectives and knowledge. This should greatly improve our ability to design and manage the landscape, and to implement biological control strategies based on scientific understanding of ecological processes.

Acknowledgments I thank Y. Mandelik, R. Yonah and two anonymous reviewers for their comments on drafts of the manuscript; R. Yonah for the help in the manuscript preparation; and the Academy of Science and Humanities (ISF grant $574 / 07$ ) for funding my recent work on CBC and BCS.

\section{References}

Barbosa, P. (Ed.) (1998). Conservation biological control. New York, NY: Academic.

Bottrell, D. G., Barbosa, P., \& Gould, F. (1998). Manipulating natural enemies by plant variety selection and modification: a realistic strategy? Annual Review of Entomology, 43, 347-367.

Coll, M. (1998a). Parasitoids in diversified intercropped systems. In C. H. Pickett, \& R. Bugg (Eds.), Enhancing biological control: habitat management to promote natural enemies of agricultural pests (pp. 85-120). Berkeley, CA, USA: University of California Press.
Coll, M. (1998b). Living and feeding on plants in predatory Heteroptera. In M. Coll, \& J. R. Ruberson (Eds.), Predatory Heteroptera in agroecosystems: their ecology and use in biological control (pp. 89-130). Lanham, MD, USA: Thomas Say Publications, Entomological Society of America.

Costanza, R., d'Arge, R., de Groot, R., Farber, S., Grasso, M., Hannon, B., et al. (1997). The value of the world's ecosystem services and natural capital. Nature, 387, 253-260.

Coulson, J. R., Klaasen, W., Cook, R. J., King, E. G., Chiang, H. C., Hagen, K. S., et al. (1982). Notes on biological control of pests in China, 1979. In US Department of Agriculture, Biological control of pests in China (pp. 1192). Washington, DC: USDA-OICD.

Daily, G. C. (1997). Nature's services: societal dependence on natural ecosystems. Washington, DC: Island.

Fiedler, A. K., Landis, D. A., \& Wratten, S. D. (2008). Maximizing ecosystem services from conservation biological control: the role of habitat management. Biological Control, $45,254-271$.

Kremen, C. (2005). Managing ecosystem services: what do we need to know about their ecology. Ecology Letters, 8, 468-479.

Landis, D. A., Wratten, S. D., \& Gurr, G. M. (2000). Habitat management to conserve natural enemies of arthropod pests in agriculture. Annual Review of Entomology, 45, 175-201.

Letourneau, D. K. (1998). Conservation biology: lessons for conserving natural enemies. In P. Barbosa (Ed.), Conservation biological control (pp. 9-38). San Diego, CA, USA: Academic.

Losey, J. H., \& Vaughan, M. (2006). The economic value of ecological services provided by insects. BioScience, 56, 311-323.

Losey, J. H., \& Vaughan, M. (2008). Conserving the ecological services provided by insects. American Entomologist, 54, 107-109.

Müller, C. B., \& Brodeur, J. (2002). Intraguild predation in biological control and conservation biology. Biological Control, 25, 216-223.

Pimentel, D., Wilson, C., McCullum, C., Huang, R., Dwen, P., Flack, J., et al. (1997). Economic and environmental benefits of biodiversity. BioScience, 47, 747-757.

Straub, C. S., Finke, D. L., \& Snyder, W. E. (2008). Are the conservation of natural enemy biodiversity and biological control compatible goals? Biological Control, 45, 225237.

Thies, C., \& Tscharntke, T. (1999). Landscape structure and biological control in agroecosystems. Science, 285, 893895.

Tscharntke, T., Klein, A. M., Kruess, A., Steffan-Dewenter, I., \& Thies, C. (2005). Landscape perspectives on agricultural intensification and biodiversity-ecosystem service management. Ecology Letters, 8, 857-874.

Tscharntke, T., Bommarco, R., Clough, Y., Crist, T. O., Kleijn, D., Rand, T. A., et al. (2007). Conservation biological control and enemy diversity on a landscape scale. Biological Control, 43, 294-309.

Zhang, W., Ricketts, T. H., Kremen, C., Carney, K., \& Swinton, S. (2007). Ecosystem services and dis-services to agriculture. Ecological Economics, 64, 253-260. 